\title{
Introduction to the Special Issue: An Analysis of a Short Term Dynamic Psychotherapy
}

\author{
Diego Rocco ${ }^{1 凶}$, Francesco De $\mathrm{Bei}^{2}, \&$ Rachele Mariani ${ }^{2}$
}

In recent years there has been a growing interest in the various forms of brief psychotherapy derived from psychoanalytic principles (e.g., Alexander \& French, 1946; Mann, 1973; Strupp \& Binder, 1984), which has transformed this form of intervention into the most widely used in the field. There is now a huge amount of psychotherapeutic approaches-Kazdin alone in 1986 had already identified over 400 different psychotherapies-a number today that has certainly grown-each of which relies on its own techniques and visions of mental functioning and psychopathology. Decades of process and outcome research, however, have lead us to able to say with confidence that there is no best model of intervention but rather that all these approaches, despite their diversity, share a common therapeutic mechanism in the clinical enterprise (Norcross, 2011) and in the good functioning of the patient-therapist relationship (Lingiardi, 2002; Wampold, 2001).

Despite this agreement among clinicians and researchers on therapeutic principles that make psychotherapy an effective treatment, it is often overlooked that work on the therapeutic relationship (Hill \& Knox, 2009) requires a time "in which transferencecountertransference reactions can emerge and be explored and understood" (Jones, 2000, p. 215). Nevertheless, the fact remains that even though interesting data on the efficacy of long-term intensive treatment has recently begun to emerge (e.g., Leichsenring, 2009; Maat, Philipszoon, Schoevers, Dekker, \& De Jonghe, 2007 ), the vast majority of data available today is based on time-limited treatments.

In other words, one could (or should) ask: Does the limited number of sessions characterizing these forms of intervention allow such dynamics to unfold? Some

\footnotetext{
${ }^{1}$ Department of Developmental and Social Psychology, University of Padua.

${ }^{2}$ Department of Dynamic and Clinical Psychology, Sapienza University of Rome.

$\triangle$ Correspondence concerning this article should be addressed to Diego Rocco, University of Padua, c/o LIRIPAC, Via Belzoni, 80, 35100 Padova. E-mail: diego.rocco@unipd.it
}

authors argue that these forms of intervention are capable of immediately catalyzing the emergence of a patient's relational patterns in the relationship with the clinician, and at the same time base their healing element on these dynamics (Flegenheimer, 1977). It is, however, a clinical-theoretical assumption that has received little attention on an empirical level.

In this special issue we have set two goals. First, to analyze the psychotherapeutic process of a single case of short term dynamic psychotherapy, using different perspectives through the application of various instruments, in order to identify events which make it is possible to attribute clinical outcome; secondly, to identify features that characterize the therapeutic action of short-term psychotherapy, emphasizing, where possible, differences or similarities with respect to a traditional (long-term) therapeutic approach. Below we will present the main features of the single case which was taken into consideration and the analysis of its outcome, in order to introduce the background to the various contributions.

\section{A single-case analysis of STDP}

\section{The case of Mr. C}

The psychotherapy in question, carried out in a Psychology Service in Northern Italy, consists of a short term dynamic psychotherapy consisting of four consulting sessions, ten psychotherapy sessions and two follow ups. The first follow up was six months after the conclusion of the therapy, and the second after 16 months, each of them consisting of three sessions. The sessions were weekly, the duration of the consultation sessions and of the follow up sessions were 45/50 minutes, while the duration of the psychotherapy sessions were, depending on the phase, from $45 / 50$ minutes to 90 minutes.

The patient, $\mathrm{C}$, was a 21-year-old male university student, of medium socio-economic level, who reported a sexual problem he'd had for three years as well as some difficulties in relationships. 
Table 1. Values obtained by SCL90-R in the different phases

\begin{tabular}{lccc}
\hline Scales & Beginning & End of therapy & Follow up \\
\hline Somatization & .58 & .25 & .66 \\
Obsessive-compulsive & 1.80 & .70 & .80 \\
Interpersonal sensitivity & .67 & .56 & .22 \\
Depression & 1.69 & .54 & .15 \\
Anxiety & 1.30 & .80 & .40 \\
Hostility & 1.33 & .50 & .16 \\
Phobic anxiety & .29 & .00 & .00 \\
Paranoid ideation & 1.33 & 1.33 & .00 \\
Psychoticism & .90 & .60 & .00 \\
Additional items & .57 & .43 & 31 \\
Number of positive items & 53 & 42 & .36 \\
Total mean & 1.08 & .56 & \\
\hline
\end{tabular}

The psychotherapy sessions were held by a male psychotherapist with over ten years of experience and following an intervention approach based on the Short Term Dynamic Psychotherapy (STDP) introduced by Davanloo (1990), who emphasized the importance of active techniques, characterized by the use of confrontation and interpretation of the defenses that emerge. This approach was integrated with suggestions from Fosha (2000), who uses an active empathic attention to the patient.

The psychotherapy finished with the remission of the symptom, confirmed in the final follow up. Before presenting the measure of outcome utilized, we will present a narrative description of the patient (obtained using the SWAP 200; Westen, Shedler, 1999a, 1999b; Westen, Shedler, \& Lingiardi, 2003; see below).

$\mathrm{C}$ is a likeable person (51), who is able to use his talents, capacity and energy in an efficient and productive way (2) and he tends to be conscientious and responsible (175). Moreover he is a creative person able to see things and to face problems in an original way (121), expressing himself and talking about himself articulately (92). Despite this, he tends to be inhibited and rigid, failing to recognize or allow himself to express desire or impulses (119), and he doesn't seem to worry enough about satisfying his needs or to have the right to ask or to obtain what he deserves (88).

He has difficulties recognizing his own anger (25) and he expresses it in a passive or indirect way (78), tending to develop somatic symptoms as an answer to stress or conflicts (22). He has a specific sexual symptom that appears when he is trying to have sexual intercourse (172), so he seems to associate sexual activity with danger, both in a conscious or unconscious way (99). C tends to blame himself or to feel responsible for the negative things that happen (1) and to feel guilty (57), expressing some feelings of inferiority, inadequacy and failure (54).

In relationships he tends to be passive and unassertive (199) and is afraid of being rejected or abandoned by people who are emotionally significant for him (98).
He seems to repeatedly relive and re-experience a traumatic event from his past (81).

\section{Assessment of outcome}

We have used two instruments to assess the psychotherapy outcome: the SWAP-200 ${ }^{1}$ and the SCL90-R ${ }^{2}$. Below we report the results obtained for each tool.

As previously mentioned, SCL-90 allows two different kinds of information to be obtained: a global value of the symptom profile and a series of values for each scale. In the following table we show the value of each single scale and the global value for the beginning, the end and for the final follow-up of the therapy.

We can see that at the beginning the Obsessive-compulsive and Depression dimensions had values over 1.5, which is the significant cut-off. Comparing the three phases we can note that there is a progressive decrease of values on all scales (this fact is confirmed by the decrease of the total mean which is seen in the lower row).

\footnotetext{
${ }^{1}$ The Shedler-Westen Assessment Procedure 200 (SWAP200; Westen, Shedler, \& Lingiardi, 2003) is a Q-sort methodology. Raters allocate a score to each of the 200 items in order to define to what degree it describes the subject. The result is a personality profile that can be traced to Axis II of DSM IV TR. Using the same items the authors obtained 11 personality dimensions called " $Q$ factors" (see figure 1), broader than those reported in Axis II of DSM IV-TR (see Westen, Shedler, Lingiardi, 2003). If applied in different moments of the therapy, SWAP-200 permits the detection of personality changes. The SWAP 200 was applied at the beginning of the ther-apy and at the second follow up. It was completed by the therapist and then independently double-rated by an-other clinician. The differences between the two profiles obtained were few and not significant.

${ }^{2}$ The Symptom Check List-Revised (SCL-90-R; Deroga-tis, 1983 ) is a 90 -item self-report checklist that measures a symptom profile in 9 dimensions, on a 5-point Likert scale $(0=$ null; $4=\mathrm{a}$ lot). This tool, if used at different moments of the therapy, allows the detection of changes in the symptoms. The SCL90-R was applied before the first consultation session, after the end of the therapy and at the last follow-up.
} 
We can say that this result is consistent with the symptom remission. More specifically, the dimensions that were over the cut-off at the beginning have markedly decreased, even at the second follow-up (see column three).

In Figure 1 we present each value of the SWAP-200 $Q$ factors, at the beginning of the therapy and after the second follow-up.

At the beginning of the therapy we can note that the patient had significant traits on Dysphoria and Avoidant dimensions (scores among 50 and 60), and a strong presence, score over 60, for the Dependent dimension. Other information concerns areas of good functioning. We can see that the three dimensions which are sensitive to this aspect (Obsessive, Depressive high functioning and High functioning) have values over 50 , and this means that the patient has good resources that will be used during the therapy.

The second scoring, completed at the moment of the second follow-up, shows that all the critical dimensions decreased under the cut off level of 50 . At the same time there was an increase of the Obsessive, Depressive-high functioning and High functioning dimensions.

In summary, the results highlighted by the instruments are consistent with both the clinician's evaluation and the symptom remission data. On the basis of this data we think it is possible to claim that the change observed involved not only the symptomatology but also the personality structure.

\section{The present Special Issue}

In the first article, the therapeutic process is analyzed considering a para-verbal aspect (speech-rate) present in patient-therapist communication. The para-verbal level of communication, while being conceptualized within the multiple code theory (Bucci, 1997), has never been tested empirically. In this paper we investigate the relation between speech rate and linguistic aspects of the referential process, then providing a theoretical reflection based on studies of infant research (e.g., Beebe \& Lachmann, 2002).

The second paper analyzes the referential activity of the entire course of treatment through the use of computerized dictionaries. The macro-processual level, analyzed through language measures, allows us to identify moments of symbolization and re-elaboration of the patient's narrative. Moreover, it is possible to identify changes in the modalities of verbalization that may be related to outcome data.

In the third paper, the quality of the therapeutic alliance is evaluated through the Collaborative Interaction Scale (CIS; Colli \& Lingiardi, 2009), in order to be able to investigate the development and vicissitudes of the therapeutic alliance in this form of psychotherapy.

In the fourth paper an inquiry is made into the evolution of the patient-therapist interaction pattern and the patient's prevailing pattern of transference-evaluated by means of the Psychotherapy Process Q-set of Enrico Jones, traditionally applied to long-term treatment (Ablon, Levy, \& Smith-Hansen, 2010). The interaction structures identified are traced to the changes found in the Core Conflictual Relationship Theme of the patient, allowing for reflection on the role that alternating patterns of interaction have on the patient's intrapsychic level of change.

Finally, the last paper written by Alessandra De Coro tackles the task of providing an overview of these results, their critical reading and a link, in terms of differences and/or similarities, with the wider literature and

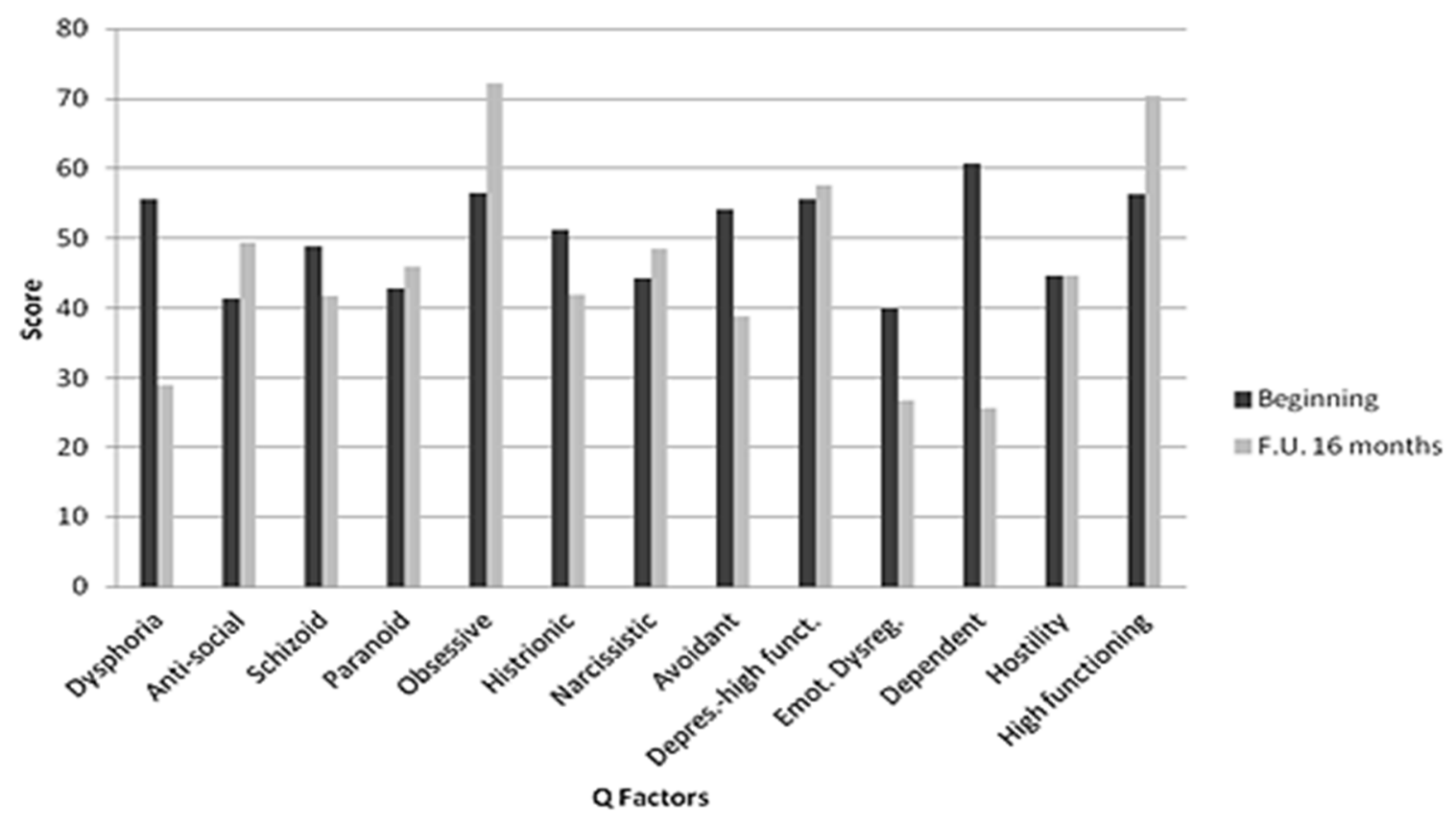

Figure 1. Q-values at the beginning of therapy and at the second follow up. 
empirical data. Since we have attempted to investigate the procedural variables associated to outcome in the papers making up this issue, in the following part of this introduction we will present both the characteristics of the psychotherapy that will be analyzed as well as the analysis of its outcome.

\section{References}

Ablon, J. S., Levy, R. A., \& Smith-Hansen, L. (2011). The Contributions of the Psychotherapy Process Q-set to Psychotherapy Research. Research in Psychotherapy, 14(1), 14-48.

Alexander, F., \& French, T. M. (1946). Psychoanalytic Therapy: Principles and applications. New York: Ronald Press.

Beebe, B., \& Lachmann, F. M. (2002). Infant research and adult treatment: Co-constructing interactions. Journal of the American Psychoanalytic Association, 50(2), 666-670.

Bucci, W. (1997). Psychoanalysis and Cognitive Science: A Multiple Code Theory. New York: Guilford Press.

Colli, A., \& Lingiardi, V. (2009). The collaborative Interaction Scale. A new transcript-based method for the assessment of therapeutic alliance ruptures and resolution in psychotherapy. Psychotherapy Research, 19(6), 718-734. doi: 10.1080/10503300903121098

Davanloo, H. (1990). Unlocking the Unconscious. Chichester, England: John Wiley \& Sons Ltd.

Derogatis, L. R. (1983). Administration, Scoring, and Procedures Manual for the recise Version. Baltimore: Clinical Psychometric Research.

Flegenheimer, W. V. (1977). Tecnicque of Brief Psychotherapy. Northvale, NJ: Jason Aronson.

Fosha, D. (2000). The transforming power of affect. New York: Basic Book.

Hill, C. E., \& Knox, S. (2009). Processing the therapeutic relationship. Psychotherapy Research, 19(1), 13-29. doi: $10.1080 / 10503300802621206$

Jones, E. E. (2000). Therapeutic action. Northvale, NJ: Jason Aronson.

Kazdin, A. (1986). Comparative outcome studies of psychotherapy: methodological issues and strategies. Journal of
Consulting and Clinical Psychology, 54(1), 95-105. doi: 10.1037/0022-006X.54.1.95

Leichsenring, F. (2009). Psychodynamic psychotherapy: A Rewiew of Efficacy and Effectiveness Studies. In R. A. Levy \& J. S. Ablon (Eds.), Handbook of Evidence-Based Psychodynamic Psychotherapy: Bridging the Gap between Science and Pratice (pp. 3 -27). Totowa, New Jersey: Humana Press.

Lingiardi, V. (2002). L'alleanza terapeutica. [The therapeutic alliance]. Milano: Raffaello Cortina.

Mann, J. (1973). Time-limited psychotherapy. Cambridge: Harvard University Press.

Maat, S., Philipszoon, F., Schoevers, R., Dekker, J., \& De Jonghe, F. (2007) Costs and benefits of long-term psychoanalytic therapy: Changes in health care use and work impairment. Harvard Rewiew of Psychiatry, 15(6), 289-300. doi: 10.1080/10673220701811654

Norcross, J. C. (2011) (Ed.). Psychotherapy Relationships that work: Evidence-Based Responsiveness. Second Edition. New York: Oxford University Press.

Strupp, J. L., \& Binder, H. (1984). Psychotherapy in a new key: A guide to time-limited dynamic psychotherapy. New York: Basic Books.

Wampold, B. E. (2001). The Great Psychotherapy Debate: Models, Methods and Findings. Mahwah, NJ: Erlbaum.

Westen, D., \& Shedler, J. (1999a). Revising and assessing axis II, part I: Developing a clinically and empirically valid assessment method. American Journal of Psychiatry, 156, 258272.

Westen, D., \& Shedler, J. (1999b). Revising and assessing axis II, part II: Toward an empirically based and clinically useful classification of personality disorders. American Journal of Psychiatry, 156, 273-285.

Westen, D., Shelder, J., \& Lingiardi, V. (2003). La valutazione della personalità con la SWAP-200. [Evaluating personality with SWAP-200]. Milano: Raffaello Cortina.

Received July 22, 2012

Revision received September 10, 2012 Accepted September 26, 2012 
